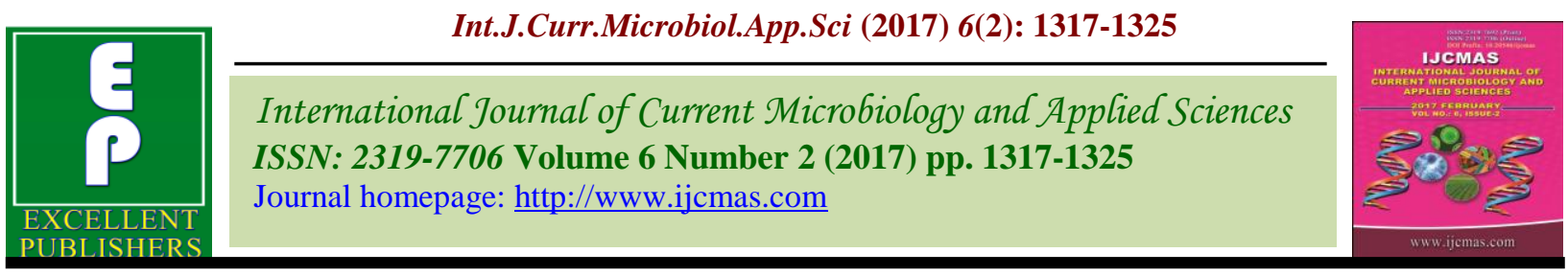

Original Research Article

http://dx.doi.org/10.20546/ijcmas.2017.602.148

\title{
Effect of Arbuscular Mycorrhizal Fungi on Growth Parameters of Sweet Corn under NaCl Salinity
}

\author{
B.P.Shinde ${ }^{1}$ and Neelima Singh $^{2} *$ \\ ${ }^{1}$ Vidya Pratishthan's Arts, Science and Commerce College Vidyanagari, \\ Baramati Dist, Pune, India \\ ${ }^{2}$ P.G. Department of Botany, Fergusson College Pune MS India \\ *Corresponding author
}

\begin{abstract}
A B S T R A C T

\begin{tabular}{|l|}
\hline K e y w or d s \\
AM fungi, Sweet \\
corn, Growth \\
parameters, $\mathrm{NaCl}$ \\
salinity.
\end{tabular}

During last few decades the mechanism of salinity tolerance in plants, from the whole plant level to cellular and gene level, has been the subject of numerous studies. However parts of the mechanism of plant salt tolerance are still mysterious. Among one third of the irrigated land is suffering from secondary salinization an alarming situation that is referred to as the "quiet crisis". We hypothesize that arbuscular mycorrhiza (AM) fungi is one of the possible Bio-ameliorator for salinity stress and play a significant role in alleviation of salt stress to greater extent. To prove our hypothesis and to investigate the effect of salt stress levels $(50,75,100 \mathrm{mM} \mathrm{NaCl})$ on growth performance of sweet corn considered as a salt sensitive and susceptible species. An experiment was carried out to determine the role of AM fungi by comparing mycorrhizal fungi inoculated sweet corn plant that are experimental to non- inoculated sweet corn plants that are control with respect to salt stress. There was a great difference in responses of sweet corn cultivars to salt stress. Plants inoculated with AM fungi shows better growth performance, higher biomass and yield as compared to non- inoculated plants.
\end{abstract}

\section{Introduction}

Salinity is one of the world's oldest and most widely distributed environmental challenges. Salinity is one of the most important abiotic stresses widely distributed in irrigated and non- irrigated areas of the world. Most of crop species i.e. bean, eggplant, onion, pepper, corn, sugarcane, potato and cabbage are sensitive to salinity, which reduce crop productivity about 6-19 \%. In general Biochemical, morphological and anatomical characteristics of crop species directly affected by soil salinity were well established (Ashraf, 2004; Ashraf and Harris, 2004; Chinnusamy et al., 2005; Parida and Das, 2005; Bhosale and Shinde, 2011a,b; Shinde et al., 2013; Shinde and Manjusha Khanna, 2014; Shinde and Ketaki Vaidya, 2014; Shinde and Jaya Thakur, 2015a, 2015b, 2016). There are many reports which concluded that salinity induces water deficit in many crops such as corn, sunflower, potato and soybean (Katerji et al., 1996; Katerji et al., 1998; Katerji et al., 2004). A primary response in plants affected by salt stress shows decrease in plant water potential to greater extent, resulting in degradation in water use efficiency, which leads to toxic damages and overall reduction in yield (Glenn and Brown, 1998; El-Hendawy et al., 2005). Growth performances and yield have been 
applied to classify salt tolerant cultivars in maize (Neto et al., 2004), Wheat (ElHendawy et al., 2005), rice (Zeng, 2005), cow pea (Murillo-Amador et al., 2006), tomato (Juan et al., 2005), Seashore Paspalum (Lee et al., 2008), and chick pea (Maliro et al., 2008).

Several studies investigating the role of AM fungi in protection against salt stress have demonstrated that the symbiosis often results in increased nutrient uptake, accumulation of an osmoregulator, an increase in photosynthetic rate and water use efficiency, suggesting that salt stress alleviation by AM fungi results from a combination of nutritional, biochemical, physiological effects (Evelin et al., 2009). It is reported that AM fungi inoculated plants grow better than noninoculated plants under salt stress (Al-Karaki, 2000; Cantrell and Linderman, 2001; Giri et al., 2003; Sannazzaro et al., 2007; Zuccarini and Okurowska, 2008). It has been reported that mycorrhizal Acacia nilotica seedlings had higher root and shoot dry weight than the non-mycorrhizal seedlings (Giri et al., 2007). Al-Karaki (2000) observed a higher shoot and root dry weight, fresh fruit yield, fruit weight and fruit number in a mycorrhizal tomato plant than in a non- mycorrhizal tomato plant. Colla et al., (2008) reported improved growth, yield, water status, nutrient content and quality of fruits of Cucurbita pepo plants colonized by Glomus intraradices when exposed to salinity stress. Enhanced growth of AM plants has been partly attributed to mycorrhizically mediated enhanced nutrient acquisition, especially better $\mathrm{P}$ nutrition (Plenchette and Duponnis, 2005; Sharifi et al., 2007). Despite all the work on salinity over the years, the solution for salinity stress problems is still far from being achieved, but several attempts were successful in improving the crop production under salt stress. In this work we have selected arbuscular mycorrhiza (AM) fungi one possible Bio-ameliorator for salinity stress and in this work we focus on
Sweet corn plant belonging to family Poaceae considered the third most important crop in the world and is grown all over the world under different climatic conditions. It is considered as a salt sensitive and susceptible species (Katerji et al., 1996; Chinnusamy et al., 2005).

\section{Materials and Methods}

Experimental set up: The study was conducted to determine the influence of AM fungi on growth parameters and yield of sweet corn treated with different concentrations of $\mathrm{NaCl}$ salt $(50,75,100 \mathrm{mM})$. The salt stress treatment was given to corn plant after 30 days at Fergusson College botanical garden. Soil used for the experiment was prepared by mixing soil, farmyard manure and sand in 3:1:1 ratio. This soil, farmyard manure and sand mixture was autoclaved, cooled overnight and then filled in plastic pots of uniform size, which comprised $8 \mathrm{Kg}$ soil/pot. Seeds of sweet corn were sown in the pot with and without mycorrhiza. Fifteen replicates of both control and mycorrhizal plants were maintained during resent investigation. The pots were placed under shade net and irrigated with normal water for one month. The mixture of AM fungi used for current experiment includes the species of Acaulospora, Glomus and Scutellospora.

The salt stress treatment was given after one month. The salt levels ranging from low$50 \mathrm{mM}$, medium-75mM and high $100 \mathrm{mM}$ determined by the use of an electric conductivity meter. Once sweet corn seedling germinated plants were irrigated with normal water on regular basis. The plants were fertilized once in a week with Hoagland solution without phosphorus. Growth parameters like root length, shoot length, number of leaf were recorded after every 30 days. After 90 days plants were harvested and roots and shoots were separated from plant 
and cobs were also separated from plant and growth parameters were measured and recorded.

\section{Results and Discussion}

Root length: The effect of AM fungi on the root length was examined under different levels of salt stress. The salt stress treatment of three desired concentrations $(50,75$ and $100 \mathrm{mM}$ ) was given to one month old sweet corn plants. It was observed that salt stress imposed at the plant significantly affect the root length. Among these three treatments, sweet corn plant treated with $50 \mathrm{mM} \mathrm{NaCl}$ concentration showed maximum root length i.e. $45.12 \mathrm{~cm}$ in control plants and $50.72 \mathrm{~cm}$ in mycorrhizal plant. The minimum root length was recorded in plant treated with $100 \mathrm{mM}$ $\mathrm{NaCl}$ concentration. It was recorded $19.10 \mathrm{~cm}$ in control plants and $22.82 \mathrm{~cm}$ in mycorrhizal plants. The plants treated with $75 \mathrm{mM} \mathrm{NaCl}$ concentration showed intermediate results. The control plants showed $29.20 \mathrm{~cm}$ long roots and mycorrhizal plants showed 36.37 $\mathrm{cm}$ (Chart 1).

Patale and Shinde (2012) reported similar results in Bt-Cotton under salt stress condition. The results of present studies also corroborated with the results of Shekoofeh and Sepideh (2011) who observed that mycorrhiza inoculated plants of Ocimum basilicum L. grown under saline conditions experienced increase in root length, dry and fresh weights of shoot. The above observations are the indication of fact that high level of salt stress and presence of salinity in soil retard the growth of root length to greater extent even in the AM fungi inoculated plants however; the roots were more healthy and longer than that of the nonmycorrhizal corn plants i.e. control in all the three treatments.

Shoot length: The increase in salinity level causes a decrease in shoot length of sweet corn plants. Among the three levels of salt stress, plant treated with $50 \mathrm{mM} \mathrm{NaCl}$ concentration showed maximum $29.55 \mathrm{~cm}$ shoot length in control plants and $38.95 \mathrm{~cm}$ in mycorrhizal plants. The minimum shoot length was recorded in plant treated with 100 $\mathrm{mM} \mathrm{NaCl}$ concentration. It was recorded $13.82 \mathrm{~cm}$ in control plants and $19.10 \mathrm{~cm}$ in mycorrhizal plants. The plants treated with $75 \mathrm{mM} \mathrm{NaCl}$ concentration showed intermediate results. The shoot length was $22.10 \mathrm{~cm}$ in control plants and $28.80 \mathrm{~cm}$ in mycorrhizal plants (Chart 2).

It was observed that the salinity has its significant impact on the growth of shoot length. These findings are in accordance with the results of Kumar et al., (2015). According to them AM-inoculated Jatropha showed better growth (shoot length, root length, shoot diameter, shoot dry weight, and root dry weight) than non mycorrhizal plants under salt stress, supporting the positive role of AM fungi in alleviation of $\mathrm{Na}_{2} \mathrm{SO}_{4}$ salinity. Datta and Kulkarini (2014) also reported similar results in Acacia arabica. According to them mycorrhiza reduced negative impact of salt stress on plant height and AM colonized plants were found to be taller as compared to non-mycorrhizal plants while exposed to various levels of soil salinity.

Leaf count: The mycorrhizal plants have shown more number of leaves than control plants under different levels of salt stress. There was a significant decrease in the number of leaves with the increase in level of salt stress (Chart 3). Among the three levels of salt stress, plant treated with $50 \mathrm{mM} \mathrm{NaCl}$ concentration showed maximum number of leaves. In control plants 8.75 leaves per plant were recorded whereas in mycorrhizal plant 10.50 leaves per plant were recorded. The minimum number of leaves was recorded in plant treated with $100 \mathrm{mM} \mathrm{NaCl}$ concentration. There were 8.00 leaves per control plants and 8.50 leaves per mycorrhizal 
plants. The plants treated with $75 \mathrm{mM} \mathrm{NaCl}$ concentration showed intermediate results with leaf count. The number of leaves was 6.50 per control plant and 7.75 leaves per mycorrhizal plant. Similar findings were observed by Khalid et al., (2016) who studied the effect of Arbuscular mycorrhizal fungi mitigating salt induced adverse effects in sweet basil (Ocimum basilicum L.).

Chart.1 Impact of salt stress and AM fungi on the root length of sweet corn plant

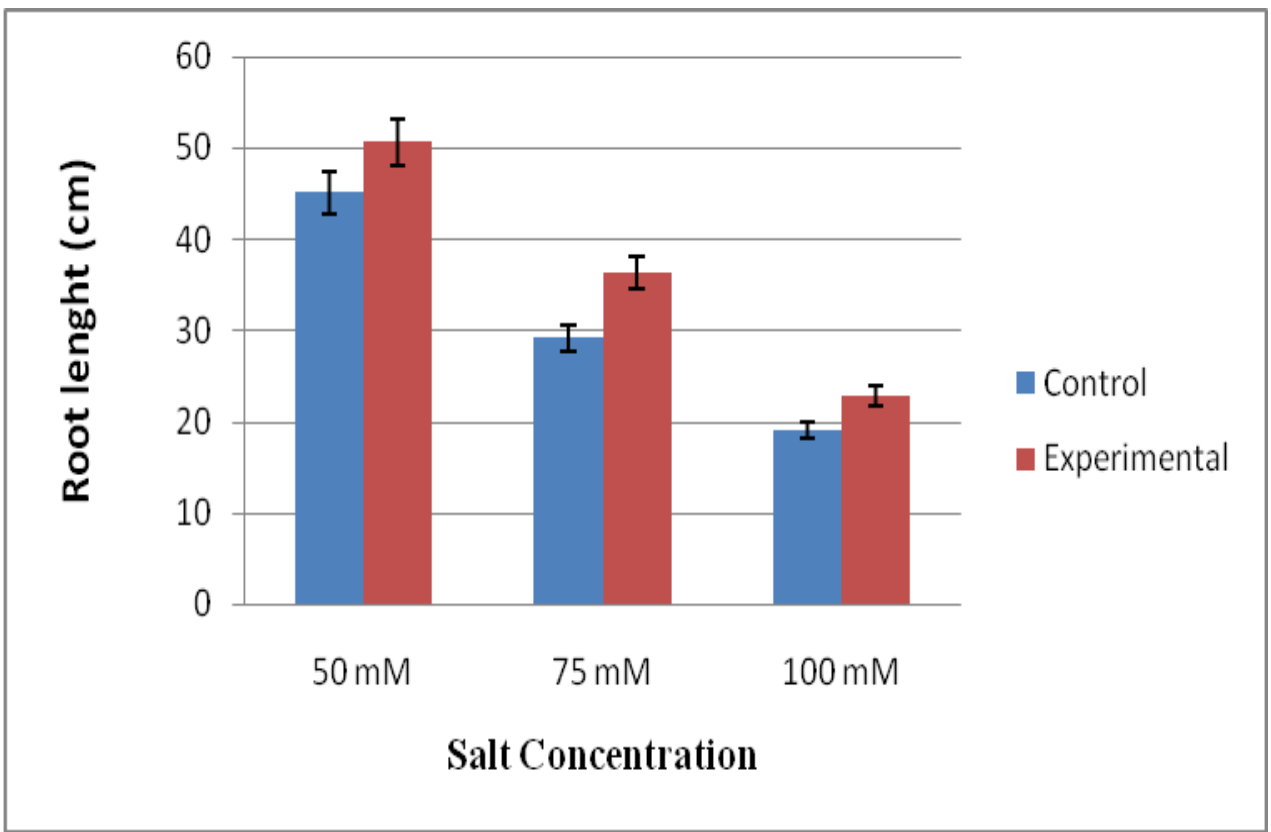

Chart.2 Impact of salt stress and AM fungi on the shoot length of sweet corn plant

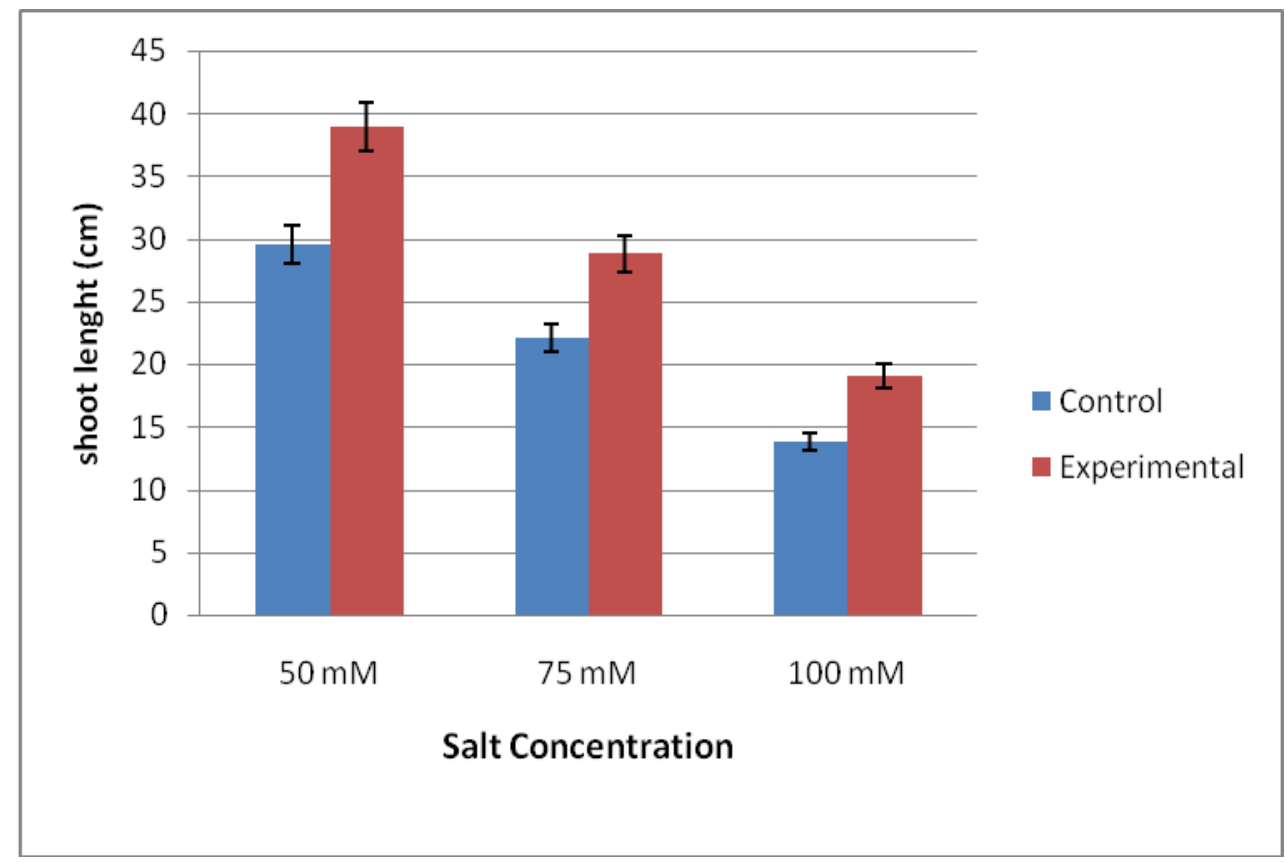


Chart.3 Impact of salt stress and AM fungi on the number of leaves of sweet corn plant

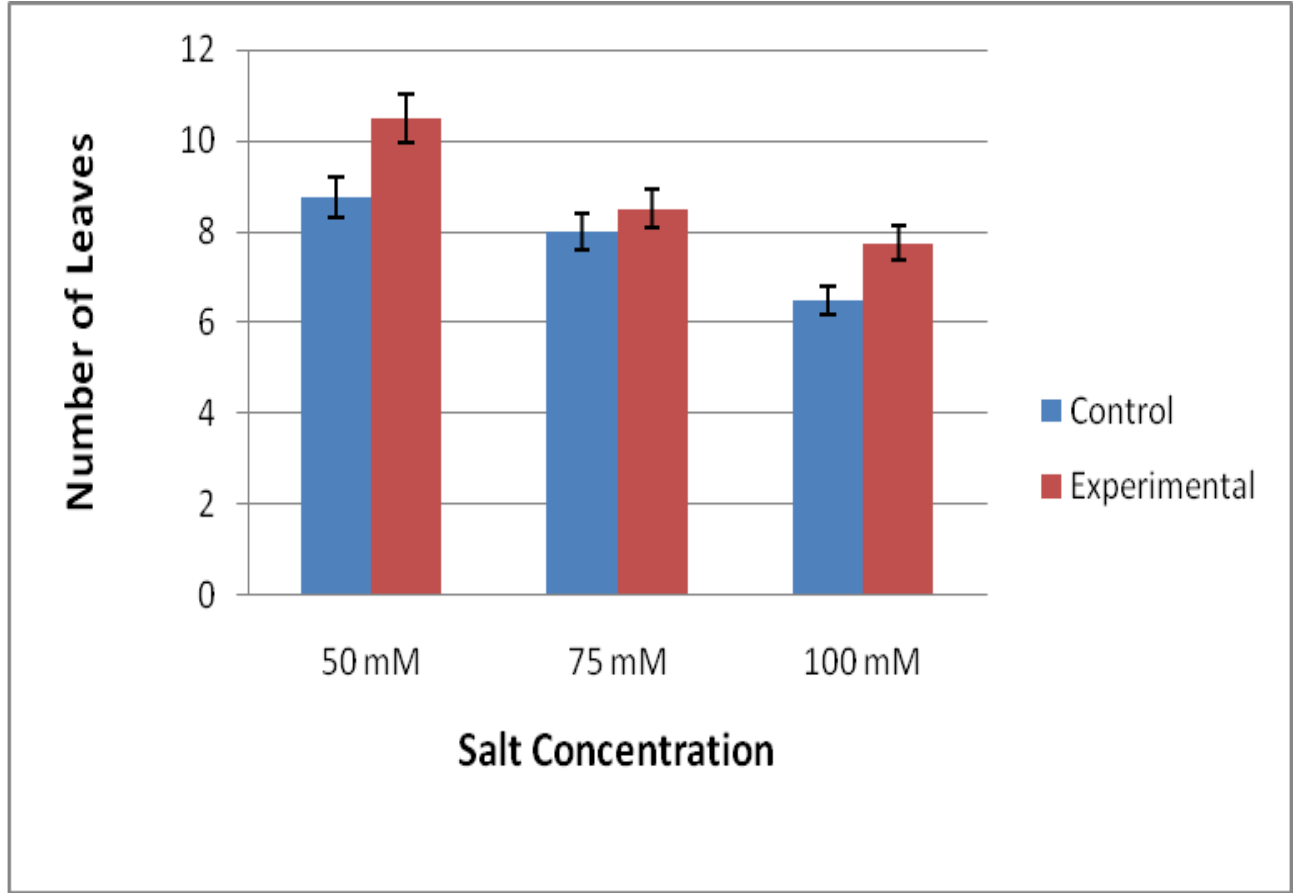

Chart.4 Impact of salt stress and AM fungi on the fresh weight of cob

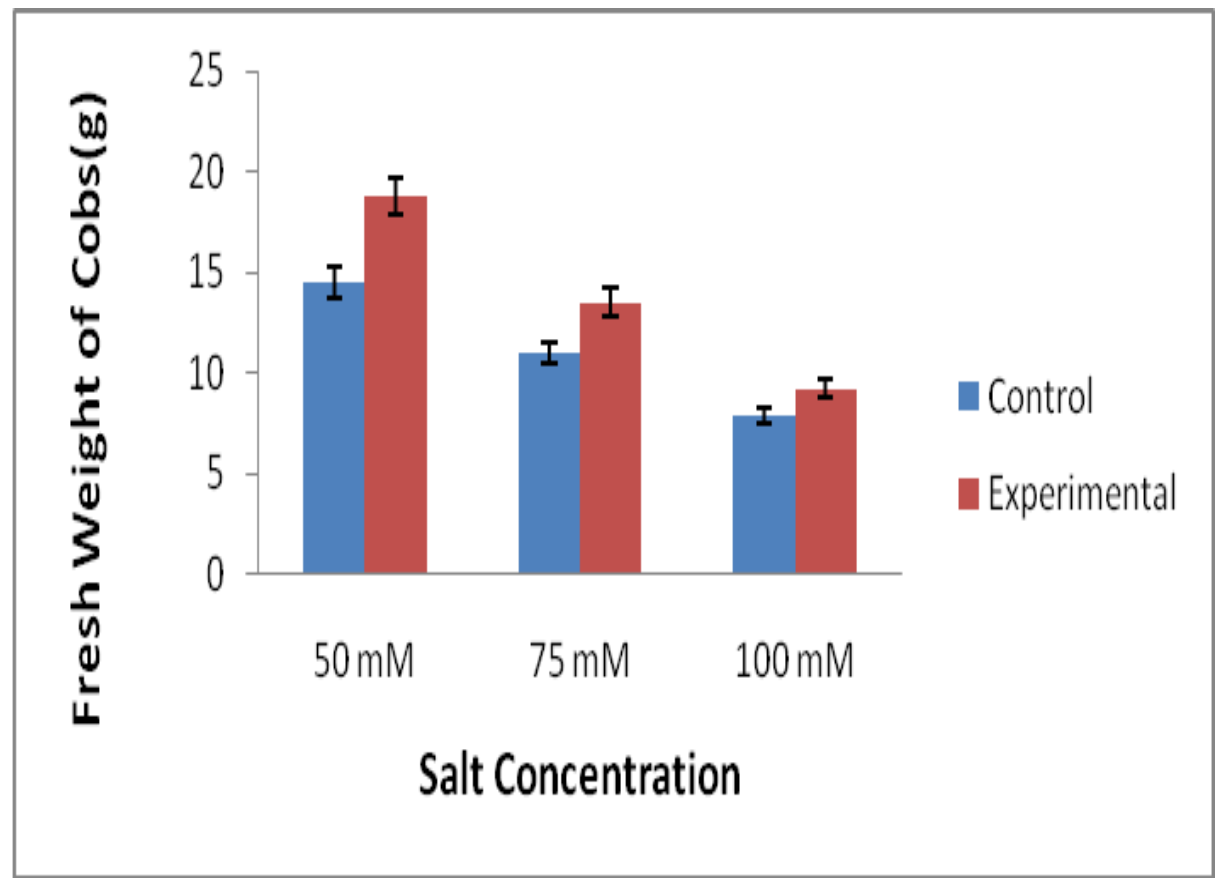


Chart.5 Impact of salt stress and AM fungi on Growth Vigour Index of sweet corn plant

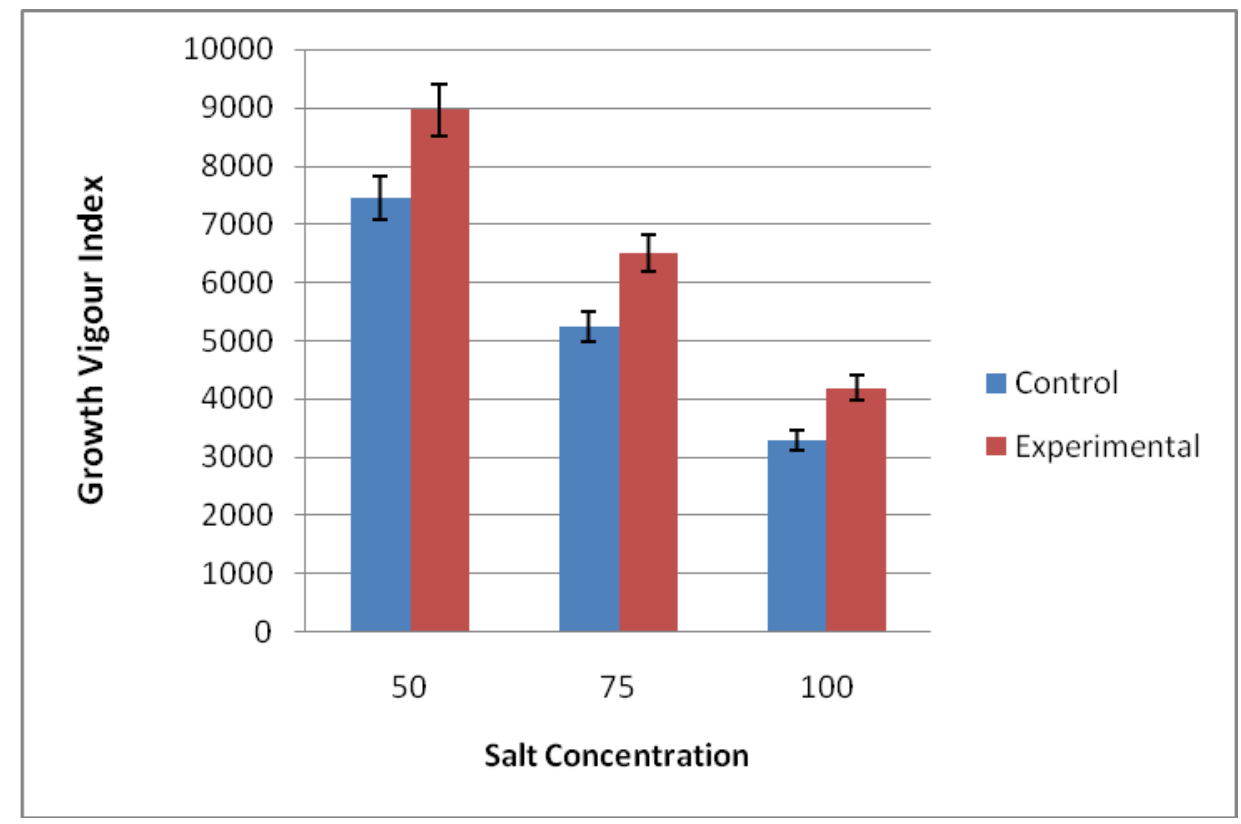

Fresh weight of cob: The fresh weight of sweet corn cob was recorded more in mycorrhizal plants as compared to control plants under different levels of salt stress. There was a significant decrease in fresh weight of cob with the increase in dose of $\mathrm{NaCl}$ salt (Chart 4). Plant treated with $50 \mathrm{mM}$ $\mathrm{NaCl}$ concentration showed maximum fresh weight of cob. It was recorded $79.50 \mathrm{gm}$ in control plants and $87 \mathrm{gm}$ in mycorrhizal plants. The minimum fresh weight of cob was recorded in plants treated with $100 \mathrm{mM} \mathrm{NaCl}$ concentration. In control plants it was recorded $66 \mathrm{gm}$ and in mycorrhizal plants it was $68 \mathrm{gm}$. The plants treated with $75 \mathrm{mM}$ salt concentration showed intermediate results. The fresh weight of cob was $74.5 \mathrm{gm}$ in control plants and $79 \mathrm{gm}$ in mycorrhizal plants. The fresh weight of sweet corn cob was recorded more in mycorrhizal plants than control plants at all the three different doses of $\mathrm{NaCl}$. Our results corroborated with the findings of Bheemareddy et al., (2010). According to them AM fungi are known to reduce the salt stress and help the host plants to produce more biomass and yield as compared to non- mycorrhizal plants.
Growth vigour index: Growth vigour index in general indicates about the overall growth of plant which include root length, shoot length, leaf count and over all yield of plant. The growth vigour index of the mycorrhizal plants was more as compared to non mycorrhizal plants. There was a significant decrease in GVI with the increase in level of salt stress (Chart 5). Plant treated with $50 \mathrm{mM}$ $\mathrm{NaCl}$ concentration showed maximum GVI. In control plants it was 7462 and in mycorrhizal plants it was 8967 . The minimum GVI was recorded in corn plants treated with $100 \mathrm{mM} \mathrm{NaCl}$ concentration. It was 3292 in control plants and 4192 for mycorrhizal plants. The plants treated with $75 \mathrm{mM}$ salt concentration showed intermediate results. The GVI was 5230 in control plants and 6505 in mycorrhizal plants. Similar results were reported by Gogoi and Singh (2011) in Piper longum plants.

In conclusion, according to the results obtained in the above study, it can be concluded that AM fungi plays a significant role in protecting plants from toxic effect of salt stress. The AM fungi helped sweet corn 
plant during salt stress which results in increase in growth performance of sweet corn plant than non-mycorrhizal plants. The above study demonstrated that salinity at higher level affects plant growth and yield. The AM fungi inoculated corn plants did well as compared to non- inoculated plants at lower level of salt concentrations. Through trials at different locations, the mycorrhizal local corn cultivars from Pune district can be used for further improvement and development to obtain local corn cultivars with salt tolerance.

\section{References}

Abbaspour, H., Saidi-Sar, S., Afshari, H. and Abdel-Wahab, M.A. 2012. Tolerance of mycorrhiza infected pistachio (Pistcia vera $\mathrm{L}$.) seedling to drought stress under glass house conditions. J. Plant Physiol., 169:704-709.

Al-Karaki, G.N. 2000. Growth of mycorrhizal tomato and mineral acquisition under salt stress. Mycorrhiza Abstract, 10: 5154.

Al-Karaki, G.N. and Al-Raddad, A.1997. Effect of arbuscular mycorrhizal fungi and drought stress on growth and nutrient uptake of wheat genotypes differing in drought resistance. Mycorrhiza, 7: 83-88.

Ashraf, M. and Harris, P.J. 2004. Potential biochemical indicators of salinity tolerance in plants. Plant Sci., 166: $3-$ 16.

Bheemareddy, V.S., Bayatnal, M.B. and Lakshman, H.C. 2010. Effect of salt and acid stress on Triticum aestivum L., Var. inoculated with Glomus fasciculatum. Libyan Agriculture Res. Centre J. Int., 1(5): 325-331.

Bhosale, K.S. and B.P. Shinde 2011a. Influence of Arbuscular Mycorrhizal Fungi on Proline and Chlorophyll content in Zingiber officinale Rosc grown under water stress. Indian $J$.
Fundamental and Appl. Life Sci., 1(3):172-176.

Bhosale, K.S. and B.P. Shinde 2011b. Effect of Arbuscular Mycorrhizal Fungi on nucleic acids and protein contents in ginger grown under water stress condition. Indian J. Fundamental and Appl. Life Sci., 1(4):126-130.

Cantrell, I.C. and Linderman, R.G. 2001. Preinoculation of lettuce and onion with VA mycorrhizal fungi reduces deleterious effects of soil salinity. Plant and Soil, 233: 269-281.

Chinnusamy, V., Jagendorf, A. and Zhu, J.K. 2005. Understanding and improving salt tolerance in plants. Crop Sci., 45: 437448.

Colla, G., Rouphael, Y., Cardarelli, M., Tullio, M., Rivera, C.M. and Rea, E. 2008).Alleviation of salt stress by arbuscular mycorrhizal in zucchini plants grown at low and high phosphorus concentration. Biol. Fertility of Soils, 44: 501-509.

Datta, P. and Kulkarni, M. 2014. Arbuscular mycorrhizal colonization improves growth and biochemical profile in Acacia arabica under salt stress. $J$. BioSci. Biotech., 3(3): 235-245.

EL-Hendawy, S.E., HU, Y., Yakout, G.M., Awad., Hafiz, S.E. and Schmidhalter, U. 2005. Evaluating salt tolerance of wheat genotype using multiple parameters. Europ. J. Agron., 22: 243-253.

Evelin, H., Kapoor, R. and Giri, B. 2009. Arbuscular mycorrhizal fungi in alleviation of salt stress: a review. Annals of Bot., 104: 1263-1280.

Giri, B., Kapoor, R. and Mukerji, K.G. 2003. Influence of arbuscular mycorrhizal fungi and salinity on growth biomass and mineral nutrition of Acacia auriculiformis. Biol. Fertility of soil, 38: 170-175.

Glenn, E.P. and Brown, J.J. 1998. Effects of soil salt levels on growth and water use 
efficiency Atriplex canescens (Chinopodiaceae. varieties in drying soil Amer. J. Bot., 85:10-16.

Gogoi, P. and Singh, R. K. 2011. Differential effect of some arbuscular mycorrhizal fungi on Growth of Piper longum L. Piperaceae). Indian J. Sci. Technol., 4(2): 119-125.

Juan, M., Rivero, R.M., Romero, L. and Ruiz, J.M. 2005. Evaluation of some nutrition and biochemical indicators in selecting salt resistant tomato cultivars. Environ. Exp. Bot., 54:193-201.

Katerji, N., Van Hoorn, J.W., Hamdy, A. and Mastrorilli, M. 2004. Comparison of corn yield response to plant water stress caused by salinity and by drought. Agric. Water manage., 65: 95-101.

Katerji, N., Van Hoorn, J.W., Hamdy, A., Karam, F. and Mastrorilli, M. 1996. Effects of salinity on water stress, growth and yield of maize and sunflower. Agric. Water Manage, 30: 237-249.

Khalid, M. E., Ehmad, S. E. and Abdallah, M. E. 2016. The impact of Arbuscular mycorrhizal fungi mitigating salt induced adverse effects in sweet basil (Ocimum basilicum L.). Saudi J. Biol. Sci., 24:170-179.

Kumar, A. S. Sharma, S. Mishra and J. F. Dames. 2015. Arbuscular mycorrhizal inoculation improves growth and antioxidative response of Jatropha curcas (L.. under $\mathrm{Na} 2 \mathrm{SO} 4$ salt stress, Plant Biosystems - An International Journal Dealing with all Aspects of Plant Biol., 149:2, 260-269.

Lee, G., Carrow, R.N., Duncan, R.R.Eiteman, M.A. and Rieger, M.D. 2008. Synthesis of organic osmolytes and salt tolerance Mechanism in Paspalum vaaginatum. Environ .Exp. Bot., 63: 19-27.

Maliro, M.F.A., Mcneil, D., Redden, B., Kollmorgen, J. F. and Pittoc, C. 2008. Sampling strategies and screening of chickpea (Cicer arietinum L.. germplasm for salt tolerance. Genet. Resour. Crop. Evol., 55:53-63.

Murillo-Amador, B., Troyo-Dieguez, E., Garcia-Hernandez, J.L., Lopez-Aguilar, R., Avilla-Serano, N.Y., Zamorasalgado, S., Rueda-Puente, E.O., andKaya, C. 2006. Effect of $\mathrm{NaCl}$ salinity in the genotypic variation in cow pea (Vigna unguiculata)during early vegetative growth. Sci. Hort., 108: 423-431.

Neto, A.D.A., Prisco, J.T., Enéas-Filho, J., de Lacerda, C.F., Silva, J.V., daCosta, P.H.A. and Gomes-Filho, E. 2004. Effects of salt stress on plant growth, stomatal response and solute accumulation of different maize genotypes. Braz. J. Plant Physiol., 16: 31-38.

Parida, A.K. and Das, A.B. 2005. Salt tolerance and salinity effects on plants: a review. Ecotoxicol. Environ. Safe, 60: 324-349.

Patale, S. W. and Shinde, B. P. 2012. Effect of salinity stress on growth performance of Bt-Cotton inoculated with AM fungi. Ad. Plant Sci., 21(1):135-139.

Plenchette, C. and Dupponois R. 2005. Growth response of the salt brush Atriplex numularia L. to inoculation with the arbuscular mycorrhizal fungus Glomus intraradices. J. Arid Environ., 61: 535-540.

Sannazzaro, A.I., Echeverria, M., Alberto, E.O., Ruiz, O.A., and Menendez, A.B. 2007. Modulation of polyamine balance in Lotus glaber by salinity and arbuscular mycorrhiza. Plant Physiol. Biochem., 45: 39-46.

Sharifi, M., Ghorbanli, M. and Ebrahimzadeh, H. 2007. Improved growth of salinitystressed soybean after inoculation withpre-treated mycorrhizal fungi. $J$. Plant Physiol., 164: 1144-1151.

Shekoofeh, E. and Sepideh, H. 2011. Effect of 
mycorrhizal fungi on some physiological characteristics of salt stressed Ocimum basilicum L. Iraninan J. Plant Physiol., 1(4): 215-222.

Shinde, B. P. and Ketaki Vaidya 2014. Influence of Arbuscular Mycorrhizal Fungi on Growth and Productivity of Lycopersicon esculentum L. Indian J. Fundamental and Appl. Life Sci., 4(2): 343-350.

Shinde, B. P. and Manjusha Khanna 2014. Impact of AM fungi on biochemical changes in potato plants. Int. J. Curr. Microbiol. Appl. Sci., 3(7): 1018-1027.

Shinde, B.P. and Jaya Thakur 2015a. Influence of Arbuscular mycorrhizal fungi on chlorophyll, proteins, proline and total carbohydrates content of the pea plant under water stress condition. Int. J. Curr. Microbiol. Appl. Sci., 4(1): 809-821.

Shinde, B.P. and Jaya Thakur 2015b. Impact of AM fungi on growth and biochemical content of pea during salt stress. $J$.
Pharmacy Res., 9(6): 402-407.

Shinde, B.P. and Jaya Thakur. 2016. The effect of coinoculation of pea plants with arbuscular mycorrhizal fungi and Rhizobium on the nodulation, growth and productivity" Int. J. Bioassay, 5(10): 4954-4957.

Shinde, S.K., B. P. Shinde and S. W. Patale 2013. The alleviation of salt stress by the activity of AM fungi in growth and productivity of onion (Allium cepa L.. plant. Int. J. of Life Sci. and Pharma Res., 3(1): 11-15.

Zeng, L.(2005. Exploration of relationships between physiological parameters and growth performance of rice (Oryza sativa L.. seedlings under salinity stress using multivariate analysis. Plant Soil, 268: 51-59.

Zuccarini, P. and Okurowska, P. 2008. Effects of mycorrhizalcolonization and fertilization on growth and photosynthesis of sweet basil under salt stress. J. Plant Nutri., 31: 497-513.

\section{How to cite this article:}

Shinde B.P. and Neelima Singh. 2017. Effect of Arbuscular Mycorrhizal Fungi on Growth Parameters of Sweet Corn under $\mathrm{NaCl}$ salinity. Int.J.Curr.Microbiol.App.Sci. 6(2): 1317-1325. doi: http://dx.doi.org/10.20546/ijcmas.2017.602.148 